\title{
Kajian Teknik Aplikasi Drainase Bawah Tanah dengan Menggunakan Bahan Baku Lokal
}

DOI 10.18196/pt.2016.051.14-19

\author{
Momon Sodik Imanudin ${ }^{1}$, Bakri $^{1}$, dan Androni Tambunan ${ }^{2}$ \\ ${ }^{1}$ Research Center for Suboptimal Land, Universitas Sriwijaya, Jalan Sriyaja Negara Ilir Barat I Palembang Sumatera Selatan; ${ }^{2}$ Jurusan Ilmu \\ Tanah, Universitas Sriwijaya, Jalan Sriyaja Negara Ilir Barat I Palembang Sumatera Selatan \\ Email:momon_unsri@yahoo.co.id
}

\begin{abstract}
ABSTRAK
Permasalahan budidaya tanaman pada lahan tadah hujan setelah padi adalah lahan masih terlalu basah untuk tanaman palawija, sementara untuk tanaman padi akan mengalami kekeringan pada fase generatif. Untuk itu diperlukan teknologi penurunan kadar kelembaban tanah agar tanaman palawija bisa segera ditanam setelah padi. Penelitian bertujuan mengkaji aplikasi penggunaan sistem drainase bawah tanah untuk menurunkan ketergenangan air. Bahan baku lokal digunakan agar bisa diadopsi dengan mudah oleh petani, karena penggunanan pipa paralon masih terlalu mahal. Adapun bahan pengaliran drainase dibuat dari kumpulan sabut kelapa dan ranting kayu. Sebagai media uji dilakukan dengan menggunakan media tekstur tanah lempung liat berpasir dan pasir. Hasil uji pengaliran menunjukkan bahwa kemampuan pengaliran pada sabut kelapa, lebih rendah dari ranting kayu yaitu berturut-turut 0,37 dan 0,48 liter/detik. Dan kemampuan maksimal pengaliran ditunjukkan pada tanah pasir yaitu 0,75 dan 1,93 liter/detik. Kondisi lahan dengan modulus drainase 10mm/hari dan struktur bahan ranting kayu digunakan di lapangan dengan jarak antar saluran adalah $10 \mathrm{~m}$, maka dalam 1 ha terdapat 10 jalur pipa, sehingga kemampuan debit menjadi $69 \mathrm{~m}^{3} / \mathrm{jam}$. Oleh karena itu perlu waktu pembuangan air sebesar 100/69=1,45 jam. Ini berarti bahwa potensi pembuangan dengan menggunakan sistem drainase ini layak digunakan terutama pada tekstur ringan seperti lempung liat berpasir.

Kata Kunci: Drainase bawah tanah, Sabut kelapa, Ranting kayu
\end{abstract}

\begin{abstract}
Problems crop cultivation on rain fed land after rice is still too wet for crops, while for rice crop will experience drought on the generative phase. The technology was required to decrease the moisture content of the soil so that crops can be planted after rice. The study aims to examine the application of the use of the underground drainage system to lower the water logging. Local raw materials were used in order to easily adopted by farmers, because common uses of the pipe is still too expensive. The drainage material was made of a collection of coconut husk and wood twigs. As a test medium performed using texture medium sandy clay loam soil and sand. The test results showed that the ability of the drainage flow on coconut fiber, lower than that of wood sticks consecutive 0.37 and 0.48 liters / sec. And the maximum flow capability was shown in the sandy soil of 0.75 and 1.93 liters / sec. Condition of the land with drainage modulus $10 \mathrm{~mm} /$ day and the structure of materials was used in the field of wood sticks with inter-channel spacing is $10 \mathrm{~m}$, then there is a $10 \mathrm{in} 1 \mathrm{ha} \mathrm{pipeline,} \mathrm{so} \mathrm{the} \mathrm{ability} \mathrm{to} \mathrm{discharge} \mathrm{to} 69 \mathrm{m3} / \mathrm{h}$. Therefore, it took time for water discharge at 100/69 = 1.45 This means that the potential of using systematically drainage disposal is fit for use primarily in the light texture such as sandy clay loam. Keywords: Subsurface drainage, Coconut fiber, Wood twigs
\end{abstract}

\section{PENDAHULUAN}

Kunci pengelolaan di lahan basah adalah bagaimana petani mampu mengendalikan muka air tanah pada kedalaman yang optimum untuk menciptakan kondisi kelembaban yang sesuai bagi perakaran tanaman (Imanudin et al., 2010; Bakri et al., 2013). Permasalahan sering terjadi pada saat budidaya tanaman palawija setelah padi, dimana tanah masih dalam kondisi basah, sementara kalau ditanam padi lahan tidak cukup air untuk mensuplai menjelang fase generatif. Inovasi perlu dilakukan dengan memperbaiki sistem yang ada dimana pengendalian muka air sejauh ini hanya dilakukan secara terbuka (surface drainage). Sistem terbuka yang saat ini diterapkan hanya efektif pada lahan dengan kategori rendah, 
karena pada lahan kategori sedang-tinggi seringkali menyebabkan terjadi kelebihan pembuangan air (over draiange), oleh karena itu inovasi sistem drainase bawah tanah merupakan metode yang tepat karena pembuangan air bisa dikontrol sesuai dengan keperluan. Pada tanahtanah pasang surut kategori tadah hujan bahkan pengendalian sistem drainase bawah tanah bisa berfungsi sebagai retensi air dan irigasi bawah tanah (Imanudin dan Bakri, 2014).

Drainase bawah tanah telah diaplikasikan pada tanaman padi. Instalasi pipa bawah tanah ditanam pada kedalaman $0,9 \mathrm{~m}, 0,65 \mathrm{~m}$ dan jarak antar saluran $30 \mathrm{~m}$ dan $15 \mathrm{~m}$. Hasil penelitian menunjukkan drainase dangkal dan rapat lebih efektif dalam mengendalikan muka air tanah. Aplikasi sistem ini telah bisa menanam tanaman palwija di musim basah (Abdullah, et al., 2013). Berdasarkan kriteria ASABE (2008) menerangkan bahwa jarak antar saluran bervariasi antara 7-15 $\mathrm{m}$ dan yang umum digunakan adalah $10 \mathrm{~m}$, dengan kedalaman pipa adalah $50 \mathrm{~cm}$, atau dengan variasi antara $20-35 \mathrm{~cm}$.

Menurut Helmer et al (2014) penggunaan sistem drainase bawah tanah memiliki berbagai keuntungan yaitu dapat meningkatkan produktivitas lahan pada lahan yang sering tergenang. Kondisi ini dengan penurunan muka air maka lahan bisa lebih cepat ditanami tanpa menunggu musim kemarau. Selain itu dapat meningkatkan aerasi tanah, mempercepat pengeringan lahan dan memperbaiki kondisi perakaran tanaman. Aplikasi Drainase bawah tanah juga mampu menurunkan pencemaran dimana pencucian nitrat bisa dikurangi sampai 36\% dan 29\% (Helmers, et al., 2014).

Ditambahkan oleh Yun et al (2010), bahwa penggunan drainase bawah tanah mampu mengurangi kelebihan air di permukaan lahan, dan peningkatan produksi pertanian antara 10 $25 \%$.

Sejauh ini pipa drainase bawah tanah masih produk impor dan relatif mahal, ujicoba penggunaan dengan menggunakan paralon masih relatif mahal yaitu memerlukan biaya lebih kurang Rp.18.000.000,-/ha. Oleh karena itu perlu dicari media pengaliran yang murah dan mudah didapat. Salah satu alternatif adalah dengan menggunakan bahan baku lokal yaitu dengan menggunakan sabut kelapa, dan kumpulan ranting kayu. Makalah ini akan menyajikan hasil pengujian penggunaan pipa berbahan sabut kelapa dan ranting kayu untuk media pengaliran drainase bawah tanah.

\section{BAHAN DAN METODE}

Tempat dan Waktu

Penelitian ini dilakukan di laboratorium Fisika Tanah Jurusan Ilmu Tanah, Fakultas Pertanian Universitas Sriwijaya pada bulan September 2013 sampai dengan Mei 2014

\section{Alat dan Bahan}

Bahan - bahan yang digunakan dalam penelitian ini adalah : 1) Tanah Lempung Berpasir, 2) Pasir , 3) Sabut Kelapa, 4) Ranting Kayu , 5) ijuk, dan 6) ember

Alat- alat yang digunakan adalah : 1) Bak, 2) Pipa Tanah Liat, , 3) Meteran, 5) Stopwacth, 6) Kain kasa, 7) alat-alat tulis, dan 8) Kamera Digital.

\section{METODE PENELITIAN}

Metode penelitian yang dilakukan dalam penelitian ini adalah menggunakam metode eksperimen yang dilakukan di laboratorium fisika dan areal kampus yang bertempat di belakang Jurusan Tanah Fakultas Pertanian Universitas Sriwijaya. 
Rancangan teknis bak uji pengaliran dapat dilihat pada Gambar 1 dan 2. Sementara gambar bangunan yang sudah jadi terbuat dari semen dapat dilihat pada Gambar 3. Gambar 4 dan 5 menunjukkan bahan lokal yang digunakan sebagai media pengaliran drainase bawah tanah bahan ranting kayu dan sabut kelapa.

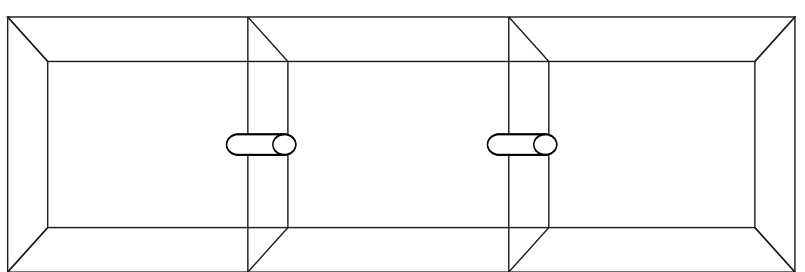

Gambar 1. Desain bak tampak atas dengan panjang 314 dan lebar 150 dalam $103 \mathrm{~cm}$.

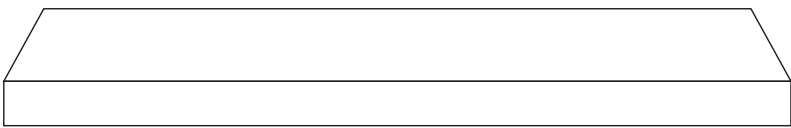

Gambar 2. Desain bak tampak samping

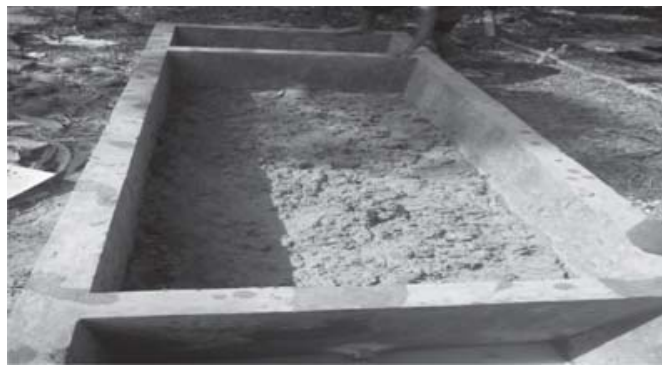

Gambar 3. Bak yang digunakan sebagai penelitian

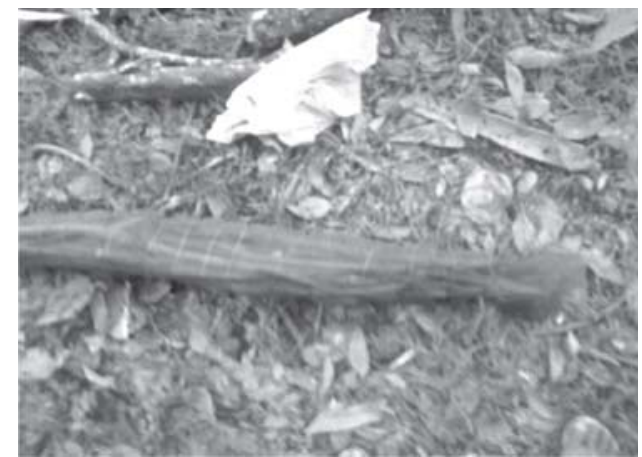

Gambar 4. Desain ranting kayu untuk drainase bawah tanah

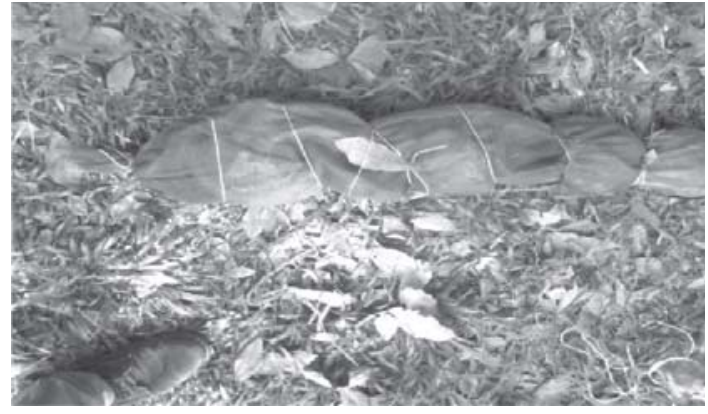

Gambar 5. Desain sabut kelapa untuk drainase bawah tanah

Uji di laboratorium dilakukan dengan menggunakan bak uji coba yang dirancang dengan ukuran panjang $314 \mathrm{~cm}$, dan lebar 150 $\mathrm{cm}$, tinggi $103 \mathrm{~cm}$ yang di dalamnya diisi tanah pasir, dan tanah lempung berpasir dengan ketebalan tanah $60 \mathrm{~cm}$. Bahan yang sudah dirancang seperti gambar di atas ditanam pada kedalaman $20 \mathrm{~cm}$ dari permukaan tanah dan diisi air setinggi $10 \mathrm{~cm}$. Untuk mengamati muka air tanah, dipasang meteran kain di dalam bak.

\section{Peubah yang diamati}

Peubah yang diamati dalam penelitian ini adalah :

1. Perhitungan debit air pada media pasir dan tanah lempung liat berpasir dengan persamaan

Rumus $\mathrm{Q}=\mathrm{V} / \mathrm{t}$

Dimana:

$Q=$ Debit air

$\mathrm{V}=$ Volume

$\mathrm{t}=$ Waktu

\section{Cara Kerja}

\section{Persiapan}

Pada tahapan ini, kegiatan yang dilakukan berupa :

a. Pengumpulan Studi Pustaka dan data-data pendukung dalam Penelitian.

b. Persiapan alat dan bahan yang akan 
digunakan dalam penelitian.

c. Penentuan metode dan cara kerja pembuatan

Langkah-langkah selanjutnya adalah :

a. Tanah jenis tekstur lempung liat berpasir dan pasir dimasukkan secara bergantian ke dalam bak uji coba.

b. Bahan yang sudah tersedia dilapis atau dibalut menggunakan kain kasa secara bergantian agar ada filter (penyaring), kemudian dimasukkan ke dalam bak tepat pada lubang pengaliran yang telah tersedia, dan

c. Bak diisi kembali dengan tanah lempung liat berpasir dan pasir secara bergantian.

d. Air dialirkan sehingga bak tergenang

e. Pengamatan dilakukan terhadap waktu dan volume air yang mengalir pada pipa pengeluaran

\section{Proses Pengujian di Laboratorium} Pada tahapan ini, kegiatan yang dilakukan berupa:

a. Mengukur waktu yang dibutuhkan untuk menurunkan tinggi muka air tanah dengan ketinggian $10 \mathrm{~cm}$ dalam bak yang berisi tanah lempung liat berpasir dan pasir

b. Mengetahui debit air yang keluar dan kecepatan yang dibutuhkan untuk menurunkan air setinggi $10 \mathrm{~cm}$ dari permukaan tanah.

3. Analisis potensi aplikasi di lapangan digunakan pada areal 1 ha dengan asumsi curah hujan 100 $\mathrm{mm} /$ hari

Pada tahap ini dilakukan berupa :

Analisis bahan asumsi pemasangan bahan lokal pada areal 1 ha dalam asumsi 20 baris untuk menurunkan air apabila curah hujannya $100 \mathrm{~mm} /$ hari dan untuk mengetahui kemampuan bahan lokal menurunkan air dengan bahan pasir dan sabut kelapa.

4. Pengolahan data dan Pembuatan Laporan

Data didapat dari uji pengaliran menggunakan bak uji, kemudiaan hasil pengamatan disajikan secara tabulasi. Data-data yang didapatkan kemudian di kaji untuk dibandingkan bahan mana yang paling baik dalam mengalirkan air.

\section{HASIL DAN PEMBAHASAN}

Uji Kemampuan Pengaliran

Uji Pengaliran pada Tanah Lempung Liat Berpasir

Sabut kelapa didominasi oleh pori-pori mikro oleh karena itu pengaliran air relatif lambat. Dari penelitian menggunakan media tanah lempung berpasir untuk menurunkan air dari ketinggian air $10 \mathrm{~cm}$ di atas permukaan tanah memerlukan waktu yang lama dikarenakan proses peresapan air lambat.

Dari hasil penelitian tersebut sangat jelas perbedaan waktu pengaliran drainase bawah tanah. Hal tersebut dapat dilihat dari Tabel 1, dimana bahan asal ranting kayu memiliki pengaliran yang lebih baik dibandingkan dengan sabut kelapa.

Tabel 1. Uji aliran pada Media Tanah Lempung Liat Berpasir

\begin{tabular}{llc}
\hline Ulangan & $\begin{array}{l}\text { Sabut Kelapa } \\
\text { Liter/detik }\end{array}$ & $\begin{array}{c}\text { Ranting kayu } \\
\text { Liter/detik }\end{array}$ \\
\hline I & 0,59 & 0,67 \\
II & 0,35 & 0,46 \\
III & 0,23 & 0,31 \\
\hline Rata-rata & 0,37 & 0,48 \\
\hline
\end{tabular}

Hasil pengujian pengaliran tanpa media pada pipa tanah liat menunjukkan debit aliran 0,97 liter/detik (Bakri et al., 2013) dan pada pipa paralon 0,25 liter/detik (Bakri et al., 2014). Bila 
dibandingkan dengan kapasitas pengaliran sabut kelapa dan ranting kayu maka bahan ranting kayu memiliki debit pengaliran yang lebih besar oleh karena itu bahan ranting kayu bisa menggantikan pipa paralon. Namun demikian dalam teknis di lapangan ranting kayu harus dibalut dengan bahan seperti jaring ikan, atau kawat nyamuk untuk menghindari penyumbatan tanah.

\section{Analisis Potensi Pemanfaatan Bahan Lokal di Lapangan (1 ha)}

Aplikasi di lapangan menggunakan bahan ranting kayu. Pertimbangannya adalah bahan ini mudah didapat di lapangan. Ranting kayu juga bisa digantikan bambu atau kayu gelam. Dari uji laboratorium menunjukkan kemampuan pengaliran dari ranting kayu adalah 1,93 liter/detik lebih tinggi 8 kali dari bahan paralon.

Kondisi lapangan rawa pasang surut memiliki iklim basah dengan curah hujan maksimum bulanan sekitar 300-400 mm. Ini berarti modulus drainase adalah sekitar $10 \mathrm{~mm} /$ hari. Sistem drainase harus mampu membuang air dengan ketebalan $10 \mathrm{~mm} /$ hari, atau setara dengan $0,01 \mathrm{~m} \times 10.000 \mathrm{~m}^{2}=100 \mathrm{~m}^{3} /$ hari. Bila kemampuan pengaliran pipa adalah 0,48 liter/ detik atau setara dengan $1,7 \mathrm{~m}^{3} / \mathrm{jam}$. Bila jarak antar saluran adalah $10 \mathrm{~m}$, maka akan ada 10 jalur pipa, sehingga kemampuan debit menjadi $17 \mathrm{~m}^{3} / \mathrm{jam}$. Oleh karena itu perlu waktu pembuangan air sebesar 100/17 $=5$ jam 42 menit atau kita ambil nilai atas sebesar 6 jam. Angka masih ini layak untuk proses drainse lahan dan lebih cepat dibanding dengan bahan pengaliran dari pipa paralon. Durasi 6 jam masih memungkinkan memanfaatkan drainase pasang surut, bila durasi surut biasanya 6-8 jam efektif. Perhitungan di atas tidak selamanya tepat tergantung kondisi hujan dan masukan air pasang. Pada lahan tipologi A yang memiliki karakteristik selalu menerima air pasang baik pasang besar maupun kecil, kondisi air terlalu berlebih dan durasi surut tidak mampu untuk membuang air melalui drainase bawah tanah. Sistem drainase bawah tanah hanya cocok untuk lahan tipologi B dan $\mathrm{C}$.

Untuk lahan tipologi B, pada aplikasinya kondisi air pasang harus dikendalikan dengan jalan menahan air pasang menggunakan pintu air. Oleh karena itu aplikasi di lapangan pada lahan pasang surut masih memerlukan sarana bangunan pengendali minimal pintu air di tingkat tersier.

\section{SIMPULAN DAN SARAN}

Simpulan

Kesimpulan yang didapat dari hasil penelitian ini adalah :

1. Hasil uji pengaliran di laboratorium menunjukkan struktur pengaliran bawah tanah bahan ranting kayu menunjukkan hasil yang lebih cepat dibandingkan dengan sabut kelapa.

2. Analisis hidrologis menunjukkan bahan ranting kayu dengan pemasangan pada jarak antar saluran $10 \mathrm{~m}$, pada lahan 1 ha mampu membuang air dengan modulus drainase $10 \mathrm{~mm} /$ hari pada waktu 6 jam. Kondisi ini hanya bisa dikendalikan pada lahan tipologi $\mathrm{B}$ atau $\mathrm{C}$, yang memiliki suplai dari air pasang sedikit. Untuk tipologi lahan A aplikasi drainase bawah tanah tidak efektif.

\section{Saran}

Berdasarkan pertimbangan bahan baku di lapangan maka potensi sabut kelapa dan ranting kayu cukup tersedia di lapangan. Oleh karena itu penggunaan struktur instalasi bawah tanah 
bisa menggunakan kombinasi keduanya, dimana sabut kelapa bisa digunakan di bagian dalam, dan di bagian luar ranting kayu.

Untuk aplikasi di rawa pasang surut, sistem pembuangan sangat tergantung pada durasi air surut, oleh karena itu bila air pasang masih masuk maka drainase bawah tanah tidak bisa berjalan. Untuk itu diperlukan bangunan pengendali di tingkat tersier berupa pintu kelep.

\section{DAFTAR PUSTAKA}

Abdullah, D. N., Seyed M. M., Ali. S. Farid. E. M. Hossein. M. 2013. Effect of subsurface drainage on water balance and water table in poorly drained paddy fields ASAE (2008) Design of Subsurface Drainage In 'ASAE. Standards EP 480 MARI1 998 (R2008).

Bakri Momon S.I. Masreah B., Johanes 2013. Analisis Potensi Pengendalian Muka Air Tanah dengan Menggunakan Sistem Drainase Bawah Tanah Dalam Mendukung Peningkatan Indek Pertanaman di Rawa Pasang Surut. Seminar PUR PLSO, Palembang.

Bakri Robiyanto H.S. dan Andrew, D.G. 2014. Uji Kemampuan Rembesan Air Pipa Drainase Berbahan Baku Liat, PAsir dan Serbuk Gergaji. Prosiding Seminar Nasional INACID, 16-17 Mei, 2014. Palembang. ISBN: 978-602-70580-0-2.

Imanudin, M.S., Bakri., 2014. Kajian Budidaya Jagung pada Musim Hujan di Daerah Reklamasi Rawa Pasang Surut dalam upaya Terciptanya Indeks Pertanaman 300\%. Prosiding Seminar Nasional INACID 16 - 17 Mei 2014, Palembang - Sumatera Selatan. ISBN 978-602-70580-0-2.

Bakri. Imanudin, M.S., Masreah B. 2013. Pengembangan Sistem Drainase Bawah Tanah Melalui Pengunan Pipa Tanah Liat untuk Pengendalian Muka Air Tanah di Daerah Rawa PasangSurut. Prosiding Seminar Nasional Lahan Suboptimal "Intensifikasi Pengelolaan Lahan Suboptimal dalam Rangka Mendukung Kemandirian Pangan Nasional", Palembang 20-21 September 2013. ISBN 979-587-501-9

Imanudin, M.S., , Armanto, E, And Susanto, R.H. 2010. Developing Strategic Operation Of Water Management In Tidal Lowland Agriculture Areas Of South Sumatera, Indonesia. Paper presented in The 6th Asian Regional Conference of ICID"Yogjakarta, 14 Oktober 2010.

Helmer. M. Christianson, R. Brenneman, G. Locker dan Pederson, C. 2014. Water table, drainage, and yield response to drainage water management in southeast lowa. Journal of Soil and Water Conservation 2014 69(1):5A 10A;doi:10.2489/ jswc.69.1.5A.

Jung, K.Y., Yun, E.S., Park K.D., Lee, Y.H, Hwang, J.B., Park Y., Edwin, P.R. 2010. Effect of subsurface drainage for multiple land use in sloping paddy fields. 19th World Congress of Soil Science, Soil Solutions for a Changing World. 1 - 6 August 2010, Brisbane, Australia. Published on DVD. 